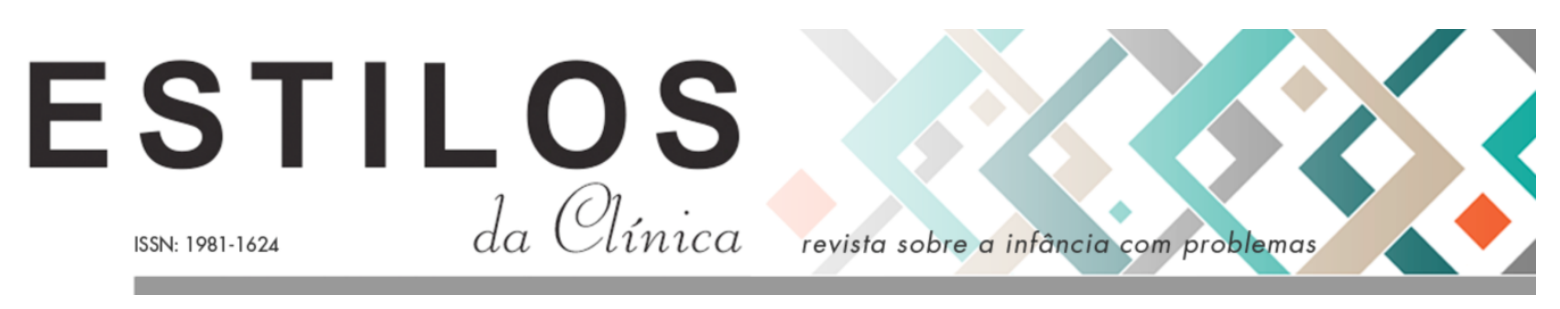

DOI: https://doi.org/10.11606/issn.1981-1624.v26i3 p494-508.

Dossiê

\title{
A potência da Educação Infantil e do pequeno semelhante para a não fixação de sinais de risco de autismo nas crianças
}

\author{
Dorisnei Jornada da Rosa; Andrea Gabriela Ferrari; Kellen Evaldt Arrosi
}

\begin{abstract}
Resumo. O presente artigo faz parte de um projeto de pesquisa-intervenção realizado em Escolas de Educação Infantil, utilizando a Metodologia IRDI. Em uma das escolas participantes da pesquisa foram percebidos sinais de risco de autismo em três bebês acompanhados. Neste escrito objetiva-se refletir sobre a importância do coletivo educacional, da interação entre os colegas e da intermediação das educadoras para identificar e desarmar condições que poderiam estar entravando o processo constitutivo dos bebês com sinais de risco de autismo. No acompanhamento realizado, evidenciou-se a função do pequeno semelhante (colega) como importante e potencializadora da constituição psíquica e do desenvolvimento da aprendizagem dos bebês que se encontravam com sinais de risco de autismo.
\end{abstract}

Palavras chave: risco de autismo; educação infantil; função do semelhante; psicanálise; dispositivos clínicos.

\section{La potencia de la Educación Infantil y del pequeño semejante para la no manutención de las señales de riesgo de autismo en los niños}

Resumen. Este escrito es parte de una investigación-intervención a través de la Metodología IRDI, realizada en Jardines de Infancia. En uno de los jardines, se percibió en tres bebés acompañados señales de riesgo de autismo. Se propone, para este escrito, pensar sobre la importancia del colectivo educacional, de la interacción entre compañeros y de la intermediación de las maestras para identificar y desarmar algunas de las condiciones que podrían estar dificultando el proceso constitutivo de los bebés. En el acompañamiento realizado se evidenció la función del pequeño semejante (compañero) como importante y potenciadora de la constitución psíquica y del desarrollo del aprendizaje de los bebés que se estaban con señales de riesgo de autismo.

Palabras clave: riesgo de autismo; educación infantil; función del semejante; psicoanálisis; dispositivos clínicos.

\footnotetext{
* Psicóloga e terapeuta em Estimulação Precoce. Psicanalista da Clínica em Tempo e membro da Associação Psicanalítica de Porto Alegre, Doutoranda da Faculdade da Educação da Universidade Federal do Rio Grande do Sul (UFRGS), Porto Alegre, RS, Brasil. E-mail: dorisneijornada@yahoo.com.br

** Professora do Programa de Pós-Graduação Psicanálise: Clínica e Cultura e do Departamento de Psicanálise e Psicopatologia da Universidade Federal do Rio Grande do Sul (UFRGS). Co-coordenadora do Núcleo de Estudos em Psicanálise e Infâncias (NEPIs). Porto Alegre, RS, Brasil. E-mail: andreagaferrari@gmail.com

*** Psicóloga. Pesquisadora do Núcleo de Estudos em Psicanálise e Infâncias (NEPIs) da Universidade Federal do Rio Grande do Sul (UFRGS). Porto Alegre, RS, Brasil. E-mail : kellenevaldtarrosi@gmail.com
} 


\title{
The power of Early Childhood Education and the little resemblant towards not-fixing signs of risk of autism in children
}

\begin{abstract}
This article is part of a research-intervention project carried out in Early Childhood Schools using the IRDI Methodology. In one of the schools participating in the research, signs of risk of autism were detected in three babies who were followed. This paper aims to reflect on the importance of the educational collective, the interaction with colleagues, and the intermediation of the educators to identify and disarm conditions that could be hindering the constitutive process of babies with sings of risk of autism. In the follow-up performed, the function of the little resemblant (other children) was highlighted as important and enhancing in the psychic constitution and in the development of the learning of the baby that is with signs of autism.
\end{abstract}

Keywords: risk of autism; child education; similar function; psychoanalysis; clinical devices.

\section{Le pouvoir de l'éducation de la petite enfance et autres pour ne pas corriger les signes de risque d'autisme chez les enfants}

Résumé. Cet article fait partie d'un projet de recherche-intervention réalisé dans les écoles d'éducation de la petite enfance (école maternelle) en utilisant la méthodologie IRDI. Dans l'une des écoles participant à la recherche, signes de risque d'autisme ont été remarqués chez trois bébés surveillés. Cet article vise à réfléchir sur l'importance du collectif éducatif, de l'interaction entre copains et de l'intermédiation des éducateurs pour identifier et désarmer les conditions qui pourraient entraver le processus constitutif des bébés présentant des signes de risque d'autisme. Dans le suivi réalisé, la fonction du petit bonhomme (collègue/copain) s'est avérée importante et potentialisant la constitution psychique et le développement des apprentissages chez les bébés au risque d'autisme.

Mots-clés: risque d'autisme; éducation des enfants; fonction du semblable; psychanalyse; dispositifs cliniques.

Os primórdios da concepção de creche, que significa "manjedoura" no idioma francês, apontam para uma concepção assistencial de tal instituição. De acordo com Rizzo (1984), a creche tinha por objetivo servir como espaço para as crianças permanecerem durante o período em que suas mães estivessem trabalhando. No século XVIII e XIX, a educação das pequenas crianças sai do âmbito familiar e passa a estar vinculada também ao espaço da creche. Com a crescente industrialização e ascensão das mulheres ao mercado de trabalho, o poder público se viu pressionado a aumentar o número de creches (Machado, 1997). Nesse caminho, a Constituição de 1988 decretou que a creche passasse a ser um direito da criança, uma opção da família e um dever do Estado. A Lei de Diretrizes e Bases da Educação Nacional (1996) estabelece no art. $4^{\circ}$ que o dever do Estado com a educação escolar pública será efetivado mediante a garantia de oferta obrigatória e gratuita de Educação Básica a partir dos 4 anos de idade. $\mathrm{O}$ acesso de crianças de outras idades (zero a 3 anos e 11 meses) à Educação Infantil configura-se como opção da família. $\mathrm{O}$ berçário ${ }^{1}$ ainda é, portanto, um espaço optativo de cuidado aos bebês no Brasil.

A função pedagógica da escola infantil foi sendo ampliada na contemporaneidade. Ela parece também realizar funções de suplência, funcionando como continuação da transmissão de marcas familiares (Crespin, 2016) e produção de aprendizagens entre os pares. Isso vem se corporificando devido às demandas sociais de atender crianças em grupo de berçários e às

1 Para subsidiar o trabalho pedagógico nas Escolas Comunitárias de Educação Infantil é fundamental considerar o Documento de Orientações construído pela Secretaria Municipal de Educação, no qual é indicado, para a composição dos berçários, 12 crianças e 2 adultos por turno de atendimento (Orientações Pedagógicas, 2019). 
necessidades de seus pais retornarem ao trabalho antes dos bebês completarem seis meses de idade. Dessa forma, pode-se dizer que a educação infantil está em evidência, ao passo que os educadores estão referenciados como participantes da subjetivação e como produtores de marcas psíquicas nos bebês (Mariotto, 2009).

A escola infantil se pronuncia, então, como mais um lugar privilegiado de subjetivação, de criação de condições estruturais e de promoção de aprendizagens para as crianças pequenas com sinais de risco de autismo. O nodal nos nossos escritos é a ideia de que a escola infantil vem se abrindo para ser também ponto de condensação entre o familiar e o institucional, entre o educador e a criança, entre esta e seu par (colega), pois se nota que, nestes espaços de convivência, armam-se vínculos e pequenas identificações entre os pequenos bebês/semelhantes. Nesse rumo, estando os bebês agrupados nos espaços de berçários 1 e 2 , com idades de 0 a 1 ano e 1 a 2 anos, vem constituindo-se momentos ricos de intervenção e trocas entre bebês que apresentam sinais de autismo, seus colegas e cuidadores.

Encontramos em nossa pesquisa grandes possibilidades nos berçários. A rotina da educação infantil torna-se um lugar importante de intervenção, uma vez que os bebês estão convivendo com seus semelhantes, com educadores e pesquisadores. Nesse cotidiano do berçário, notamos que a demanda e a presença de bebês diversos produziram formas singulares de aberturas psíquicas nos bebês que apresentavam sinais de autismo. Supomos que, quando os bebês pertencem ao grupo do berçário, a diferença e a identificação ao par - que se encontra bem podem possibilitar a ocorrência de um certo espelhamento na construção da imagem e do eu das crianças. Como exemplo, adiantaremos o caso do bebê Hugo ${ }^{2}$ que, ao imitar seus colegas e responder seus apelos para andar, foi incluído no grupo e passou a brincar junto, até chegar ao final do ano do B2 produzindo um brincar compartilhado. Dessa maneira, parece necessário e inovador ampliar essas referências e investigar a "função do semelhante" (Kazahaya, 2017) na participação do processo constituinte de bebês com sinais de risco de autismo, uma vez que, ao compartilharem o espaço coletivo do berçário e a rotina na educação infantil, tornam-se sujeitos pertencentes a um grupo.

Tal questão se apresenta como ainda mais importante na medida em que as escolas infantis municipais conveniadas à Prefeitura de Porto Alegre estão recebendo muitos bebês que apresentam sofrimento psíquico e problemas em seu desenvolvimento. Nesse passo, a educação infantil torna-se um campo potente para a psicanálise em extensão (Kupfer et al., 2009), onde o cuidar, tratar, educar e compartilhar com os pares refletem a importância da intervenção ser realizada o mais cedo possível, logo após se detectar sinais de sofrimento psíquico nos bebês.

\section{O autismo precoce}

De acordo com Laznik (2013), a ausência de troca de olhares entre o bebê e sua mãe, estendendo-se também a outras pessoas de seu convívio, constitui uma hipótese sobre sinais de autismo precoce durante os primeiros meses de vida. Mesmo havendo tal hipótese, considerase esse um tempo de constituição subjetiva em construção (Jerusalinsky, 2018), ainda não podendo se apresentar um diagnóstico ou estrutura psíquica definida ${ }^{3}$. A constituição psíquica

2 Os nomes foram alterados no intuito de manter o sigilo das identidades dos bebês.

3 Estrutura psíquica indecidida é uma nomenclatura utilizada por Julieta Jerusalinsky (2018) ao relatar o trabalho de detecção precoce de sofrimento psíquico em crianças, através da utilização do instrumento IRDI. A autora afirma que as crianças 
do bebê é estruturada por três tempos pulsionais e, no autismo, há uma falha no terceiro tempo (Laznik, 2013). Esse terceiro tempo apresenta-se como o de fazer-se objeto de desejo do outro, quando o bebê passa a se oferecer à satisfação de seus cuidadores. A falha no terceiro tempo do circuito pulsional evidencia-se nos bebês que não respondem às tentativas de olhar dos seus pais ou cuidadores, renunciando ao gozo deles. Nota-se que os bebês com esses sinais ficam fechados em si mesmos, o que torna muito difícil para os cuidadores exercerem suas funções. É da concepção de autismo trabalhada por Laznik sobre os três tempos do circuito pulsional que partimos neste escrito.

Bernardino (2015) se refere ao autismo como uma possível patologia de borda. Tal borda pode ser entendida como uma suspensão, sendo uma escolha entre se alienar ou não se alienar ao significante. Ou seja, o bebê se permite ou não ser representado pelos significantes, pela Linguagem, pelas palavras que vêm do Outro. Porém, essa escolha pode passar por momentos de indecisão na definição de estrutura, sendo possível abrir aí um tempo fértil para o trabalho entre alienação e separação. Entende-se a alienação como a operação de alienar-se ao desejo do agente que faz a função materna, e a separação como a operação de incidência da função paterna ou de um terceiro na relação da criança com seu Outro primordial (Lacan, 1964/1985). Dessa maneira, compreende-se que tal intervalo propõe caminhos para a não-fixação de uma estrutura autista, podendo abrir janelas pulsionais de um brincar compartilhado (Wanderley, 2013) frente às intervenções do educador e à interação do bebê com seus pares no contexto da educação infantil. Nesse sentido, psicanalistas apontam que, para uma criança, nada melhor que outra criança junto (Volvonich, 1993, apud Kupfer,Voltolini \& Pinto, 2010). O coletivo se constrói na igualdade e diferença entre pares, os quais, nos berçários, reúnem bebês de diferentes raças, gêneros, comunidades, culturas e estruturações psíquicas em constituição. O que será que um bebê que está bem tem a contribuir com outro que apresenta sinais de autismo? E vice-versa? Esses são questionamentos que guiaram o nosso olhar no acompanhamento à escola e que servem de norteadores para o presente escrito.

\section{A pesquisa IRDI e os bebês com sinais de autismo em uma Escola de Educação Infantil na cidade de Porto Alegre}

A pesquisa "O impacto da Metodologia IRDI na prevenção de risco psíquico em crianças que frequentam creche no seu primeiro ano e meio de vida" (Ferrari; Silva \& Cardoso, 2014), realizada em Porto Alegre, teve como direção norteadora a observação da relação dos bebês com suas educadoras. Ela surgiu a partir da experiência com o instrumento IRDI (Kupfer et al., 2009). Os IRDIs (Indicadores clínicos de Risco para o Desenvolvimento Infantil) permitem avaliar questões sensíveis ao desenvolvimento de zero aos dezoito meses. A construção dos indicadores foi realizada com base em quatro eixos teóricos, correspondentes às quatro operações constituintes de um sujeito psíquico (Kupfer et al., 2009): Suposição do Sujeito, Estabelecimento de Demanda, Alternância Presença-Ausência e instalação da Função Paterna. A Suposição de Sujeito diz respeito a uma antecipação, realizada pelo cuidador, da presença de um sujeito psíquico, ainda não constituído, no bebê, a qual permitirá justamente tal constituição; o Estabelecimento da Demanda engloba a interpretação pelo cuidador dos gestos do bebê como

pequenas apresentam suas estruturas psíquicas em construção. Concordamos com essa nomenclatura e vemos muitas aberturas e movimentos nas estruturas psíquicas de bebês com sinais de risco de autismo a partir da intervenção de quem realiza a função materna no campo da educação infantil. 
um pedido endereçado a ele, interpretando assim a própria demanda como sendo do bebê, que passa a responder a isso; o eixo Alternância Presença-Ausência refere-se às descontinuidades na satisfação do bebê e na presença do cuidador principal, que vão permitir a substituição da presença real do objeto por sua representação simbólica; o eixo Função Paterna diz respeito à entrada de uma "terceira instância" nas relações desse bebê, o que estabelece certos parâmetros para tais relações e opera na relação bebê-cuidador uma separação, fundamental para a constituição de uma noção de Eu separado do outro (Kupfer et al., 2009).

A partir desses eixos, baseados na teoria psicanalítica, formularam-se trinta e um indicadores clínicos, divididos em quatro faixas etárias: zero a quatro meses, quatro a oito meses, oito a doze meses e doze a dezoito meses. Tais indicadores tornaram possível observar o surgimento de funções psíquicas nos primeiros anos de vida da criança, considerando que esse processo depende do laço que se estabelece entre ela e seu cuidador (mãe, pai ou substitutos). A presença dos indicadores revela desenvolvimento, enquanto sua ausência refere à possibilidade de risco na constituição psíquica (Kupfer et al., 2009).

Para o andamento da pesquisa, foi constituído um grupo vinculado ao Programa de PósGraduação Psicanálise: Clínica e Cultura da Universidade Federal do Rio Grande do Sul: o Núcleo de Estudos em Psicanálise e Infâncias. O grupo reúne-se semanalmente para estudo, leitura dos diários clínicos (Silva, Oliveira \& Ferrari, não publicado), análise de vídeos e discussão de casos. O projeto com a Metodologia IRDI (Ferrari, Silva \& Cardoso, 2014) atentou-se para a observação da presença ou não de sinais de risco psíquico nos bebês e, dessa maneira, foi possível pensar e realizar intervenções e encaminhamentos a tempo de não se fixar patologias futuras.

No acompanhamento semanal realizado no ano de 2018 no berçário 1 de uma escola de Educação Infantil conveniada à Prefeitura de Porto Alegre, pertencente à zona leste da cidade, foram apontados, pelas educadoras, três bebês de 0 a 12 meses que teriam suspeita de risco de um autismo futuro. A um desses bebês o diagnóstico foi dado por um médico neurologista, os demais eram supostos dessa maneira pelas educadoras com base em traços percebidos nesses bebês, baseados no que escutavam na cultura sobre autismo. Os pesquisadores refletiam e perguntavam às educadoras e aos pais dos bebês de onde vinham esses diagnósticos, quem os havia dado e porque os comportamentos dos bebês os faziam pensar em autismo. Nesse sentido, foram realizadas intervenções (que serão posteriormente apontadas neste escrito), a fim de abrir reflexões a respeito do estabelecimento de psicopatologias em crianças tão pequenas.

Além dos apontamentos realizados pelas educadoras, os três bebês também preocupavam pela ausência ou não observância de alguns indicadores da Metodologia IRDI. É relevante destacar que os indicadores não se propõem a servir como um check-list, mas sim como guia do olhar na observação da relação entre o bebê e o adulto (Kupfer \& Bernardino, 2018). Os pesquisadores perceberam, tendo os IRDIs como pano de fundo, uma precariedade na consolidação do terceiro tempo do circuito pulsional (Laznik, 2013) na relação dos três bebês anteriormente referidos com suas educadoras, atentando-se para o risco de um autismo futuro.

No ano de 2019, durante o retorno dos pesquisadores à escola para dar seguimento ao acompanhamento com a Metodologia IRDI, as crianças que no ano anterior apresentavam sinais de sofrimento psíquico mostraram-se inseridas no coletivo, estabelecendo brincadeiras, disputando brinquedos e a atenção dos adultos em sala de aula. Percebeu-se que os colegas chamavam e realizavam demandas a esses bebês. As educadoras, por sua vez, incentivavam que as crianças respondessem às propostas dos colegas. Portanto, pareceu-nos importante pensar a função do semelhante (outro bebê) perante o bebê que apresenta sinais de risco de 
autismo precoce nas salas de berçário. Nessa direção, começamos a observar os efeitos e funções dos colegas ao estarem em um espaço compartilhado, no oferecimento de imitações, brincadeiras, espelhamentos, estímulos e percepções.

A importância do par e do coletivo para bebês com sinais de risco de autismo precoce que frequentam berçários nas escolas de educação infantil é um tema ainda pouco trabalhado em Psicanálise e na Pedagogia, fazendo-se necessário pesquisas e intervenções no campo da educação infantil que considerem a relação do bebê com outro bebê. Pensamos, portanto, que o berçário revela-se como mais um espaço de intervenção a tempo para que tais sinais de risco não se consolidem.

\section{Metodologia}

A referência desta pesquisa-intervenção de caráter longitudinal é a psicanálise em extensão (Kupfer et al., 2009), centrada em uma abordagem qualitativa de construção de casos e embasada no campo teórico investigativo de inserção na educação infantil. Os debates entre estes campos de saber (psicanálise, aprendizagem e educação infantil) alertam para a importância dos discursos educacionais e dos laços com as crianças pequenas para o processo de constituição psíquica. Os instrumentos utilizados para a coleta de dados foram os diários clínicos (Silva, Oliveira \& Ferrari, não publicado) e as observações das interações entre os próprios bebês, bem como entre estes e suas educadoras.

Com um foco no acompanhamento qualitativo dos bebês e na promoção de saúde, utilizouse como guia do olhar e instrumento de leitura das observações a Metodologia IRDI e seus eixos (considerados como operadores de fundação de um sujeito psíquico). Foram observadas nas crianças as potencialidade e eventuais dificuldades constitutivas na criação de vínculos e no relacionamento com o outro. Kupfer \& Bernardino (2018) consideram que, além de possibilitar a realização de uma leitura dos bebês e de seus processos constituintes, os IRDIs são capazes de apontar uma desconexão na relação entre eles e seus cuidadores, justificando uma intervenção a tempo. As intervenções que acompanhavam as observações nos berçários eram realizadas em ato, de modo a servir de apoio ao fazer cotidiano do educador (Ferrari, Fernandes, Silva \& Scapinello 2017; Silva, Medeiros, Arrosi \& Ferrari, 2021). Algumas dessas intervenções incluíam, por exemplo, dar voz a um bebê que ainda não fala, lançar uma pergunta diante das práticas instituídas e servir como modelo especular através do brincar.

Como campo de pesquisa foi escolhida uma Escola de Educação Infantil localizada na zona leste de Porto Alegre. A escola conta com dois berçários, com dez bebês em cada um, sendo três com sinais de risco de autismo precoce, os quais foram acompanhados no ano de 2018. As observações foram realizadas semanalmente durante um turno, tanto em 2018 quanto em 2019. Houve gravações em vídeo dos bebês em momentos de atividades educativas e em interação. Também foram realizadas entrevistas e conversas com as educadoras a respeito das crianças. $\mathrm{O}$ acompanhamento foi realizado mediante assinatura dos pais de Termos de Consentimento Livre e Esclarecido, autorizando a participação de seus filhos. Ademais, o projeto de pesquisa em questão passou pelo Comitê de Ética em Pesquisa do Instituto de Psicologia da Universidade Federal do Rio Grande do Sul e encontra-se inscrito na plataforma Brasil ${ }^{4}$.

4 Número do CAAE: 22411213.9.0000.5334 


\section{Os bebês com sinais de risco de autismo no berçário 1}

Foi indicado aos pesquisadores no início do acompanhamento, em 2018, através das duas educadoras do berçário 1, que haviam bebês com sinais de autismo precoce. Apenas um deles tinha diagnóstico dado por neurologista, os outros eram assim apontados a partir de suposições das educadoras com base naquilo que haviam escutado sobre comportamentos de crianças autistas. Analisando o comportamento desses bebês e as especificidades das suas relações com o outro, os pesquisadores perceberam dificuldades na instalação do tempo em que o bebê se oferece como objeto de desejo de seus cuidadores (Laznik, 2013), além de alguns indicadores do IRDI estarem ausentes ou não observados. Tendo isso em vista, tornou-se importante voltar a atenção para os sinais de risco de sofrimento psíquico nos bebês e realizar intervenções no sentido de contribuir para a não instalação de uma psicopatologia futura.

A respeito do bebê Hugo, as educadoras apontavam um atraso no desenvolvimento: ele não brincava e não olhava, tinha asma e não ficava em pé com apoio passivo. Além disso, era um bebê muito quieto, que pouco demandava, sendo escassos os momentos em que eram observadas interações entre ele e as educadoras. Na marcação com o IRDI, realizada quando Hugo possuía 12 meses de idade, 7 indicadores encontravam-se ausentes dentro da faixa etária dos 8 a 12 meses (14. A educadora percebe que alguns pedidos da criança podem ser uma forma de chamar a sua atenção; 15. Durante os cuidados corporais, a criança busca ativamente jogos e brincadeiras amorosas com a educadora; 16. A criança demonstra gostar ou não de alguma coisa; 17. Educadora e criança compartilham uma linguagem particular; 18. A criança estranha pessoas desconhecidas para ela; 20. A criança faz gracinhas e 21. A criança busca o olhar de aprovação do adulto) e outros 3 não foram observados (15. Durante os cuidados corporais, a criança busca ativamente jogos e brincadeiras amorosas com a educadora; 19a. A criança possui objetos prediletos em casa e 19b. A criança possui objetos prediletos na creche).

A bebê Bianca tinha diagnóstico de autismo pelo neurologista. Ela não dormia na hora do sono coletivo, permanecendo bastante agitada, e tinha algumas crises epilépticas. Apresentou, na marcação com o IRDI aos 11 meses de idade, 1 indicador ausente (18. A criança estranha pessoas desconhecidas para ela) e 6 indicadores não observados (15. Durante os cuidados corporais, a criança busca ativamente jogos e brincadeiras amorosas com a educadora; 16 . A criança demonstra gostar ou não de alguma coisa; 17. Educadora e criança compartilham uma linguagem particular; 19a. A criança possui objetos prediletos em casa; 19b. A criança possui objetos prediletos na creche e 21. A criança busca o olhar de aprovação do adulto).

Já o bebê André chorava muito, não comia na escola e não sustentava o olhar, questões que preocupavam as educadoras e os pesquisadores. Em sua marcação com o IRDI, realizada quando tinha 10 meses de idade, apresentou 4 indicadores ausentes (15. Durante os cuidados corporais, a criança busca ativamente jogos e brincadeiras amorosas com a educadora; 16. A criança demonstra gostar ou não de alguma coisa; 17. Educadora e criança compartilham uma linguagem particular e 22. A criança aceita alimentação semissólida, sólida e variada) e 5 indicadores não observados (18. A criança estranha pessoas desconhecidas para ela; 19a. A criança possui objetos prediletos em casa; 19b. A criança possui objetos prediletos na creche; 20. A criança faz gracinhas e 21. A criança busca o olhar de aprovação do adulto).

Tendo o instrumento IRDI como guia do olhar, os pesquisadores atentaram-se para a desconexão entre os bebês e suas educadoras, evidenciada pela ausência de vários indicadores, sendo a maioria deles pertencentes ao eixo Estabelecimento da Demanda. Tal eixo compreende as primeiras reações do bebê, como o choro, que serão reconhecidas pelo cuidador como um 
pedido que a criança endereça a ele (Silva et al., 2021). Esse reconhecimento permitirá que a criança possa de fato vir a demandar, balizando sua atividade posterior na relação com o outro ao longo da vida. A fragilidade na consolidação desse eixo de operação psíquica apontava para a falta de singularização do laço entre educadoras e bebês e de um olhar atento para as preferências e necessidades de cada criança. Dessa forma, no berçário 1 a preocupação foi promover a interação entre bebês e educadoras, onde estas oferecessem o desdobramento da função materna com cuidados, interpretação dos atos e antecipação das ações aos bebês, supondo-os como sujeitos. Também eram realizadas intervenções de forma que as educadoras se perguntassem o que os bebês estavam demandando, pedindo ou dizendo com seus choros, movimentos e olhares, no "dado a ver do corpo" (Jerusalinsky \& Berlinck, 2008).

Os objetivos principais do projeto de pesquisa no berçário 1 eram observar a função do educador com os bebês e aplicar o instrumento IRDI, de forma a intervir na relação entre eles, promovendo as quatro operações do sujeito (Kupfer et al., 2009). Além disso, ao final do ano de 2018, os pais dos bebês que apresentavam alguns sinais de sofrimento psíquico (lidos pelas educadoras como autismo) foram convidados a uma entrevista de escuta a fim de serem trabalhadas questões relacionadas à filiação, à nominação, aos cuidados e aos significantes oferecidos a seus filhos no dia a dia.

Tais entrevistas aconteciam sempre com a presença da educadora. Nelas, o dispositivo clínico oferecia um compartilhamento das funções entre cuidar e educar de ambos (pais e educadores), bem como pretendia-se desmistificar a ideia de um possível diagnóstico de autismo, singularizando as intervenções e retirando os bebês de um lugar negativo de diferença. Nessas ocasiões, também retomamos a noção de que os bebês têm estrutura psíquica indecidida (Jerusalinsky, 2018), visto que estão em constituição e sem diagnósticos definitivos, suscetíveis, portanto, a aberturas psíquicas. Isso tudo propunha que educadoras e pais fossem referenciados como participantes da subjetividade dos bebês, nas suas devidas diferenciações entre a filiação e os desdobramentos das funções parentais oferecidas no cuidar e no brincar da educadora.

\section{Os bebês no berçário 2 (idades entre 12 e 24 meses)}

Os bebês considerados autistas pelas educadoras e que preocupavam os pesquisadores, no início de 2018, por uma aparente desconexão na relação com o outro foram alvo das intervenções anteriormente mencionadas. $\mathrm{O}$ trabalho foi realizado no sentido de promover a singularização dessas crianças, incentivando que as educadoras tecessem narrativas sobre os seus comportamentos. Ao mesmo tempo, foi possível retirar os bebês de um lugar pejorativo de diferença, abrindo possibilidades de intervenções com eles, ao invés de restringi-los em decorrência das dificuldades encontradas em seus desenvolvimentos.

No início de 2019, quando os bebês passaram a frequentar o berçário 2, Hugo estava com 1 ano e 5 meses e mostrava-se ainda como um bebê mais quieto, retraído e com pouca interação com as crianças. Porém, ao longo das semanas de acompanhamento, percebeu-se uma função que os colegas, mais ativos e extrovertidos, desempenhavam: demandar de Hugo respostas e atitudes na disputa de brinquedos. Tal situação, junto com a ajuda de seus pais e educadoras, fizeram com que o bebê começasse a caminhar sem dificuldades no decorrer do ano.

Foram observadas cenas interessantes que davam a ver a função do semelhante no berçário 2: Hugo "cochichava algo" a seus colegas, excluindo os adultos. Ele intrigava os pesquisadores, 
visto que com os colegas balbuciava, cochichava e caminhava pela sala. Ao longo dos dias, começou a disputar corrida com André, Bianca e os demais colegas, apesar do andar balançante ainda o acompanhar. Também ia para baixo da mesa em brincadeiras de esconde-esconde. Houve um dia em que caiu e a colega Bianca lhe levantou e disse: "vem!". Ele viabilizou o pedido dela e levantou-se, sem chorar. Hugo respondia aos colegas, mas se mostrava muito tímido ao olhar dos adultos da sala (pesquisadores e educadores), bem como a responder a eles. Uma das pesquisadoras, intrigada com a disponibilidade dele aos pares, começou a chamá-lo e dizer: "vamos bater papo?" Ele vinha ao encontro da pesquisadora, mas depois cochichava ao ouvido de André algo ininteligível ao adulto. Dessa cena advém um questionamento importante, o qual apontamos como possível norteador de estudos futuros: há uma linguagem própria de bebês?

Os pesquisadores intensificavam as intervenções e lhe chamavam, ofereciam brincadeiras e pediam que ele falasse o que queria. No final de 2019, Hugo falava um pouco com educadores e pesquisadores, mas ria muito e brincava de esconder com os colegas. Ele parecia feliz e com boa interação com seus semelhantes. No que se refere à marcação com o IRDI de Hugo na faixa etária dos 12 aos 18 meses, apenas 2 indicadores estavam ausentes (24. A criança suporta bem as breves ausências da educadora e reage às ausências prolongadas e 25a. A criança interessase pelo corpo da educadora).

A bebê Bianca, com 1 ano e 5 meses, passou a dormir no horário coletivo, o que antes não fazia por apresentar epilepsia e dificuldades em pegar no sono (permanecendo agitada durante todo o período em que ficava na creche). Através de uma entrevista com sua mãe, no ano de 2018, tivemos acesso ao medo antecipado de que sua filha tivesse crises epiléticas enquanto dormia e acabasse falecendo. Mãe e bebê foram encaminhadas, nesse mesmo ano, para atendimento especializado. No ano de 2019, Bianca também passou a se oferecer e se mostrar aos pesquisadores, chamando-os para brincar. Ela disputava os brinquedos, reclamava, falava pequenas palavras e brincava de esconde-esconde e comidinha. Houve uma cena que ilustra a qualidade do vínculo e das interações de Bianca com os colegas. Ela liderou uma brincadeira de cadeiras, a qual consistia em andar de ônibus com ela mandando suas colegas sentarem e fazendo de conta que era a motorista. Em seguida, vinha pedir com o famoso vocábulo "dá", denunciando sua queixa de que a colega havia pego a cadeira de motorista. Após, ia para sua casa de brincadeirinha, embaixo da mesa e lá ficava com os outros colegas. A pesquisadora dizia "cadê a menina que foi para casa? Já está na hora de dormir. Vamos brincar de tirar uma soneca em casa?". Ela brincava de roncar e fazia que dormia. Os outros a nanavam. Havia uma menininha que lhe nanava e dizia "miga". Em sua marcação com o IRDI dentro da faixa etária dos 12 aos 18 meses, todos os indicadores estavam presentes, com exceção do 24 (A criança suporta bem as breves ausências da educadora e reage às ausências prolongadas) e do 25a. (A criança interessa-se pelo corpo da educadora), os quais não foram observados.

Já o bebê André, com 1 ano e 4 meses, ainda selecionava alimentos, pois preferia mamar no peito. O pesquisador J. lhe oferecia o arroz separado dos outros alimentos e lhe dizia "você pode comer a comida, igual ao Bento (colega maior) e ficar grande e forte". O pesquisador oferecia seu corpo para André escalar, além de brincarem de carro com mais três colegas. A partir dessa identificação com o masculino e com "ser grande", André ia se soltando e imitando os colegas. Nas refeições, às vezes olhava o prato de Bento, que roubava do prato de André o que este deixava de comer porque o arroz estava misturado com outros ingredientes. Certo dia, ao lanchar com o pesquisador e seu colega, comeu tudo e misturado. André começou a brincar com os colegas e, quando o pesquisador J. chegava, ele vinha contar e apontava para 
os pares amigos, meninos. Essas composições de grupos com o pesquisador J. parecem tê-lo ajudado na identificação com seu amigo Bento e a querer falar, comer e correr, assim como fazia o colega maior. A questão principal de André passava pela sua mãe, que iniciava o processo de retirada do seio e sentia dificuldades em oferecer outros alimentos, pois lembrava sempre que o filho teve refluxos na hora da comida na escola, quando estava no berçário 1 . Ao final do ano houve desaparecimento de seu choro e uma maior comunicação oral. Na marcação com o IRDI, nenhum indicador estava ausente, porém 2 foram assinalados como "não observado": 24. A criança suporta bem as breves ausências da educadora e reage às ausências prolongadas, e 25a. A criança interessa-se pelo corpo da educadora.

Chama-nos a atenção o fato de que os indicadores ausentes ou não observados nos três bebês durante o acompanhamento ao berçário 2 são os mesmos: 24. A criança suporta bem as breves ausências da educadora e reage às ausências prolongadas e 25a. A criança interessa-se pelo corpo da educadora. Depreende-se daí que a relação dos bebês em questão com os pares fez um papel de suplência diante da fragilidade da singularização do laço entre eles e as educadoras (fato que pode passar por vários motivos, dentre eles a alta demanda de trabalho nos berçários e a grande quantidade de bebês deixados aos cuidados de apenas duas educadoras). Com isso, evidencia-se a função do pequeno semelhante no processo de constituição psíquica das pequenas crianças, proporcionando movimentações subjetivas e estruturantes.

A partir de cenas como as descritas neste capítulo, foi possível perceber que os sinais de risco psíquico de autismo nesses bebês haviam se dissipado. Os pesquisadores observavam interações e demandas entre os colegas, e faziam intervenções e pedidos para esses bebês, os quais começaram a responder em ato, com gestos e palavras. Eles disputavam os brinquedos, os colos das educadoras e dos pesquisadores, bem como se ofereciam e se mostravam nas suas brincadeiras coletivas. Esses movimentos no sentido de estabelecer uma interação com os pares e com os adultos são aquisições esperadas em um processo de desenvolvimento saudável, evidenciando a construção de uma relação com o outro.

\section{A importância do coletivo para bebês com sinais de autismo nos berçários. O que a diversidade permite entre os pares e educadores?}

Nesta seção, serão apresentadas ideias de diferentes epistemologias, porém igualmente importantes para pensarmos acerca da funções do coletivo e do pequeno semelhante no contexto da Educação Infantil. Em uma perspectiva psicanalítica, Kupfer, Voltolini e Pinto (2010) apontam a relevância de haver uma diversidade de constituições subjetivas em um coletivo, uma vez que a ajuda que uma criança concede a outra tem valor estruturante e constituinte. Nessa direção, entende-se que a escola é uma instituição poderosa enquanto discurso social, uma vez que oferece às crianças uma certidão de pertinência: quem está na escola pode receber o carimbo de criança (Kupfer, Voltolini \& Pinto, 2010, p. 100).

Torna-se importante, portanto, pensar sobre o que uma criança que está bem nas interações e compartilhamentos próprias da fase em que se encontra pode fazer pela outra que apresenta sinais de autismo. Será que se estas últimas ficassem em casa, apenas com seus cuidadores, estariam em melhor abertura para sua estruturação psíquica? O bebê Hugo teria saído de sua exclusão e imaturidade motora se não estivesse vendo seus amigos correrem, brincarem e cochicarem coisas ao seu ouvido? Talvez sim, talvez não, não há como saber. Contudo, refletir 
sobre o processo de compartilhamento cotidiano e convivência na faixa etária dos 8 a 18 meses, bem como sobre o coletivo do berçário durante essa fase sensório-motora (Piaget, 1975) pode nos mostrar direcionamentos.

Sabemos que nessa época de vida de um bebê os aspectos estruturais e instrumentais (Forster \& Jerusalinsky, 1999) se desenvolvem conjuntamente. Ou seja, a estrutura psíquica, a aprendizagem, a interação com o meio, com a linguagem e com o brincar dependem, além do investimento dos cuidadores primordiais, da interação com o educador e com os colegas de sala. Nessa linha, se não houver olhar e propostas de brinquedos estruturantes (Rosa, 2011) e intermediação desses cuidadores (inclui-se, aqui, os educadores) no grupo do berçário, dificilmente haverá um desenvolvimento rico em aprendizagem sensório-motora e estimuladora.

Nesse sentido, alertamos que os vínculos e aquisições instrumentais e estruturais dessa fase também podem dar-se pelo vínculo com os pares, enquanto função fraterna, como caráter necessário para o semelhante tornar-se sujeito. Ao nosso ver, o grupo pode exercer função de apego, suplência parental e promoção de aprendizagem dos papéis sociais e cognitivos. Assim, tomamos os berçários como grupo de bebês sem laços cosanguínios, mas que atuam como promotores de identificação e de diversidade entre semelhantes. Consideramos essa convivência como poderoso espaço de pertencimento e produção de marcas psíquicas entre os bebês. Dessa forma, os valores seriam deslocados para os amigos escolhidos no berçário, onde os vínculos representariam uma forma de qualidade do fraterno (irmãos) (Goldsmid \& FéresCarneiro, 2011; Jaitin ${ }^{5}$, 2008; Kehl, 2000).

O psicólogo Piaget (1975), que se dedicou à psicologia e descreveu pormenorizadamente cada estágio de desenvolvimento das crianças correspondente a sistemas cognitivos específicos, apontou a importãncia da imitação entre os pares. Portanto, a convivência é necessária e promotora de aprendizagens. Segundo essa abordagem, os bebês de 0 a 2 anos que participam dos berçários estão no estágio sensório-motor, no qual a inteligência é descrita como sendo sem pensamento ou representação, sem linguagem, sem conceitos. Importante lembrar a relevância da descoberta do objeto permanente na fase de 8 a 12 meses. Esta descoberta faz diferença no bem-estar de um berçário, pois ajuda o bebê a entender que vai voltar para sua casa ao final da tarde e ser amamentado pela mãe, como no caso do sofrimento de André; no caso de Bianca, que poderá dormir e a mãe estará lá ao acordar; e no de Hugo, ao ajudá-lo a caminhar e crescer ao ser colocado em outras posturas que não sentado na cama, podendo deslocar-se, assim como fazem os colegas.

Mesmo se tratando de uma inteligência prática, a qual se determina pela percepção, vemos nestes espaços o que Piaget (1975) destaca na imitação, pois se notou uma importante forma de intervenção: imitar os colegas como inteligência sensório-motora. $\mathrm{O}$ autor descreve o desenvolvimento da imitação no período sensório-motor, em seis fases. Até a quinta fase (18 a 24 meses), o bebê pode apenas imitar modelos que fazem parte do seu repertório comportamental até o aparecimento gradual da função simbólica. A fase final do período sensório-motor (fase da imitação diferida) será quando a criança fizer a evocação simbólica da realidade ausente e sair do plano da imitação pré-representacional. Nesse sentido, observamos

5 Jaitin, R. (2008). Viscisitudes del vínculo fraterno. [Conferência]. Centro Franco-Argentino de Altos Estudios de la Universidad de Buenos Aires 
que os bebês Hugo, Bianca e André começaram a fazer imitações dos colegas, em brincadeiras de pega-pega e esconde-esconde. Eles também iniciavam um faz-de-conta, mas ainda precisando da convocação dos colegas e, por vezes, da intermediação das educadoras e pesquisadores.

Em contraponto a ordem de sucessão dos estágios de Piaget, Dolle (1987, p. 53) aponta que

estes estágios não significam cronologia fixa, pois esta é variável e depende da experiência anterior do sujeito e de sua maturação, sendo que o meio social pode acelerar ou retardar a aparição de um estádio, imitação ou mesmo impedir sua manifestação.

O autor afirma que Piaget já apontava que a interação do sujeito com o objeto também depende do meio social. Ampliando tal concepção, pensamos que a interação e saída do risco psíquico de autismo também depende do brincar compartilhado (Wanderley, 2013) entre os bebês, e não somente do oferecimento ao Outro (Lacan, 1964/1985) enquanto educador.

Ainda pensando que a aprendizagem e a passagem por estágios cognitivos depende de suas estruturações psíquicas e de seus pares, citaremos Vygotsky (1989) e sua preocupação com o meio social para potencializar o desenvolvimento das crianças. Esse autor, partindo de uma perspectiva sócio-interacionista, dá ênfase ao papel das relações sociais no desenvolvimento intelectual, pois, para ele, o homem é um ser que se forma em contato com a sociedade. A interação que cada pessoa estabelece com um ambiente torna-se, portanto, extremamente importante. Um de seus principais conceitos é a zona de desenvolvimento proximal (Vygotsky, 1989), no qual dá destaque à intervenção do adulto para que a criança desenvolva competências. Nesse sentido, é possível dizer que o bebê inserido em um coletivo educacional encontra, na interação com os educadores e com os colegas, condições para o desenvolvimento de sua zona proximal.

Seguindo os caminhos das aprendizagens das crianças, Stern (1997) coloca que os bebês precisam de uma representação do aspecto subjetivo para envolverem-se em repetidas experiências interpessoais em que as ações, afetos, percepções e imagens visuais possam, então, ser compostas juntas e ao mesmo tempo. Essa representação foi denominada pelo autor como um "esquema-de-estar-com-uma-outra-pessoa" (Stern, 1997, p. 81). As experiências cotidianas (comer, dormir e brincar) têm, portanto, uma importância física e psíquica, visto que iniciam com os pais e, gradualmente, vão construindo representações para além desse contexto. Sendo assim, os momentos emergentes e "esquemas de estar com" (Stern, 1997, p. 93), além das atividades de rotina diária na educação infantil, são formas de experiência social padronizadas pela via da repetição e ensaio-erro, envolvendo acontecimentos interpessoais. Stern (1997) ainda ressalta que o estado indiferenciado do bebê, de fusão eu/outro no início da vida, é condição para emergir o eu e o outro separado. Para tanto, ele considera que o eu é nós, e que aí o bebê se destaca como ser social, alcançando a sociabilidade.

Já em uma vertente psicanalítica, Forster e Jerusalinsky (1999) indicam que a estimulação que a criança recebe, se na medida e na qualidade adequada, favorece sua maturação. Isso se revela em todos os campos, inclusive neuronais, visto que a influência do berçário enquanto ambiente rico e estimulador pode ser absorvido como um campo de desejo e compartilhamento de experiências com os outros (Kazahaya, 2017) e com o Outro.

Nesse contexto de aprendizagem para bebês, parece que um ponto de convergência entre as ideias dos diferentes autores é a importância do meio social e da presença do educador e do outro (colega) para que o bebê que frequenta o berçário se desenvolva bem e tenha experiências estimuladoras. Um exemplo disso são os horários de brinquedo livre na rotina da sala de aula, 
que nos parece um espaço detentor de muita potência criativa entre as crianças, já que se configura como um momento em que elas brincam livremente, sem atividade pedagógica dirigida.

Um bebê com sinais de risco de autismo possui um duplo caminho a percorrer: alienar-se e separar-se do campo do Outro (que representa a figura do educador) ou relacionar-se com o pequeno outro (o colega), que se coloca entre o bebê e sua educadora. Kazahaya (2017) reflete sobre o que seria o pequeno semelhante nas formações pré-grupais e enfatiza a importância deste para o desenvolvimento e constituição psíquica. $\mathrm{O}$ autor refere-se ao "pequeno semelhante" como aquele que se apresenta para um bebê ou criança pequena ainda no início de sua constituição subjetiva:

Podemos apontar que o pequeno semelhante também pode ser um indicador clínico da formação de um espaço de confiança e amor (na relação com a mãe e/ou educador), o espaço potencial, onde o bebê pode se constituir numa base de espontaneidade e criatividade. Por exemplo, se há entre os pequenos semelhantes disputa para obter atenção do cuidador ou brinquedos, então há uma relação de confiança. Essa disputa gradualmente cederá espaço para a cooperação, marcando uma abertura social (Kazahaya, 2017, p. 97).

\section{Considerações finais}

A grande perspicácia desta pesquisa estaria em aproveitar a oportunidade para ser possibilitadora de uma interferência-em-interação na circulação e repercussão do estudo dos processos cotidianos de encontro entre os bebês e suas interlocuções, imitações e interações estruturantes dentro do espaço educacional (Informação verbal) ${ }^{6}$. Nós nos propusemos, enquanto pesquisadores, a estar em sala de aula, acompanhando a rotina, observando as interações e marcando a relevância de um olhar singular que serve como baliza para as intervenções. Servindo de ponte para o encontro entre a educadora e o bebê e entre o bebê e seus pares, acreditamos que o trabalho realizado constitui-se como potencializador da retomada do percurso constitutivo daqueles bebês que anteriormente apresentavam sinais de risco de autismo.

Ao considerarmos o que Motta (2002) aponta, que a intervenção precoce é assinalada como o mais "a tempo" possível, o que não seria a priori, mas centrada em um tempo de um trabalho em construção, pensamos que a pesquisa tornou-se, a posteriori, referenciada como uma pesquisa-intervenção de caráter longitudinal. Este escrito trouxe à tona a importância e a potência da escola infantil para a pesquisa psicanalítica. Isso por se centrar em um trabalho de construção de um sujeito que se encontra com sinais de risco de autismo precoce, tomando a proposta de prevenção com uma base estrutural: o sujeito precisa ser antecipado, pré-vindo, além do pré-visto e pré-dito no campo do Outro e dos outros (pequenos semelhantes) que convivem em um berçário.

Tivemos como objetivo refletir e potencializar o espaço dos berçários e do pequeno semelhante, na educação infantil, como facilitador e promotor de enlaces possíveis com os bebês que apresentam sinais de autismo. Dessa forma, fez parte da proposta da intervenção identificar e desarmar condições, o mais cedo possível, que poderiam estar impedindo ou dificultando o novo ser. Concordamos com Motta (2002, p.115): "é uma aposta desejante, supor

6 R. B. Ceccim, novembro de 2019. 
um sujeito ali, onde ele pode advir". Acrescentamos que ali, onde ele pode advir, é no convívio com seus pequenos semelhantes, pois "ver um amigo em outro lugar, ou ser convidado pelo amigo para ocupar outra posição, isto é o que uma criança pode fazer pela outra" (Kupfer, Voltolini \& Pinto, 2010, p. 106). Essa é uma aposta simbólica nos bebês que estão se constituindo, ver-se no outro e compartilhar com o seu par um brincar com as diferenças, com os impasses e com as produções que podem se estruturar no contexto da Educação Infantil.

\section{Referências}

Bernardino, L. M. F. (2015). Os psicanalistas e as psicopatologias da infância. In: Kamers, M., Mariotto, R. M. M., \& Voltolini, R. (Orgs.), Por uma (nova) psicopatologia da infância e adolescência (pp. 55-68). São Paulo: Escuta.

Crespin, G. C. (2016). À escuta das crianças na educação infantil. São Paulo: Instituto Langage.

Dolle, J. M. (1987). Para compreender Jean Piaget: Uma iniciação à psicologia genética piagetiana. Rio de Janeiro: Guanabara.

Ferrari, A. G.; Silva, M. R.; Cardoso, J. L. (2014). O impactor da Metodologia IRDI na prevenção de risco psíquico em crianças que frequentam creche no seu primeiro ano e meio de vida (Projeto de Pesquisa/2014), Porto Alegre, RS, Instituto de Psicologia, UFRGS.

Ferrari, A. G.; (2017). A experiência com a Metodologia IRDI em creches: pré-venir um sujeito. Revista Latinoamericana de Psicopatologia Fundamental, São Paulo, 20(1), 17-33. doi: https://doi.org/10.1590/1415-4714.2017v20n1p17.2

Forster, O. H.; Jerusalinsky, A. N. (1999). Bases neurofisiológicas da estimulação precoce. In: Jerusalinsky, A. N. (Org.), Psicanálise e desenvolvimento infantil (pp. 275-282). Porto Alegre, RS: Artes e Ofícios.

Goldsmid, R., Féres-Carneiro, T. (2011). Relação fraterna: constituição do sujeito e formaçãodo laço social. Psicologia USP, São Paulo, 22(4), 771-787. https://doi.org/10.1590/S0103$\underline{65642011005000031}$

Jerusalinsky, J. (2018) Detecção precoce de sofrimento psíquico versus patologização da primeira infância: face à lei $\mathrm{n}^{\mathrm{o}} 13438$, referente ao estatuto da criança e do adolescente. Estilos da Clínica, São Paulo, 23(1), 83-99. doi: https://doi.org/10.11606/issn.19811624.v23i1p83-99

Jerusalinsky, J.; Berlinck, M. T. (2008). Leitura de bebês. Estilos da Clínica, São Paulo, 13(24), 122-131. doi: https://doi.org/10.11606/issn.1981-1624.v13i24p122-131

Kazahaya, D. (2017). O pequeno semelhante em questão: o que bebês e crianças pequenas podem fazer pelos seus pares semelhantes na constituição psíquica e no desenvolvimento. Estilos da Clínica, São Paulo, 22(1), 83-99. doi: https://doi.org/10.11606/issn.19811624.v22ilp83-99

Kehl, M. R. (2000). Função fraterna. Rio de Janeiro: Relume Dumará.

Kupfer, M. C. M., Jerusalinsky, A. N., Bernardino, L. M. F., Wanderley, D., Rocha, P. S. B., Molina, S. E., et al. (2009). Valor preditivo de indicadores clínicos de risco para o desenvolvimento infantil: um estudo a partir da teoria psicanalítica. Latin American Journal of Fundamental Psychopathology, 6(1), 48-68. doi: https://doi.org/10.1590/S1415$\underline{47142010000100003}$ 
Kupfer, M. C., Bernardino, L. (2018). IRDI: um instrumento que leva a psicanálise à pólis. Estilos da Clínica, São Paulo, 23(1), 62-82. doi: https://doi.org/10.11606/issn.19811624.v23i1p62-82

Kupfer, M. C.; Voltolini, R. \& Pinto, F. S. (2010). O que uma criança pode fazer por outra? Sobre grupos terapêuticos. In M. C. Kupfer \& F. S. Pinto (Orgs.), Lugar de vida, vinte anos depois (pp. 97-112). Exercícios de educação terapêutica. São Paulo: Escuta/Fapesp.

Lacan, J. (1985). O seminário, livro XI: os quatro conceitos fundamentais da psicanálise. Rio de Janeiro: Zahar. (Trabalho original publicado em 1964).

Laznik, M. C. (2013) A hora e a vez do bebê. São Paulo: Instituto Language.

Lei $n^{\circ} 9394$ de 20 de dezembro de 1996. (1996). Estabelece as diretrizes e bases da educação nacional. Brasília. Recuperado de http://www.planalto.gov.br/ccivil_03/leis/19394.htm

Machado, T. P. (1997). Creche Universitária: Um sonho que se fez realidade. Londrina, PR: UEL.

Mariotto, R. M. (2009) Cuidar, educar e prevenir: as funções da creche na subjetivação de bebês. São Paulo: Escuta.

Motta, S. (2002). Prevenção em saúde mental - por que não? In: Bernadino, L. M. F., \& Rohenkohl, C. M. F. (Orgs.), O bebê e a modernidade; abordagens teórico-clínicas. São Paulo: Casa do Psicólogo.

Orientações pedagógicas (2019). Orientações Pedagógicas para Escolas Comunitárias de Educação Infantil que ofertam Educação Infantil no Município de Porto Alegre. Recuperado de $\quad$ http://lproweb.procempa.com.br/pmpa/prefpoa/smed/usu doc/anexo iii orientacoes_pedagogicas_nova_versao.pdf

Piaget, J. (1975). A formação do símbolo na criança: imitação, jogo e sonho, imagem e representação. Rio de Janeiro, RJ: Zahar.

Rizzo, G. (1984). Creche: organização, montagem e funcionamento. Rio de Janeiro, RJ: Francisco Alves

Rosa, D. J. (2011). A educação estruturante na Educação Infantil. Revista da Associação Psicanalítica de Porto Alegre, 1, 99-108.

Silva, M. R.; Oliveira, B. C.; Ferrari, A. G. (não publicado). Da experiência ao relato clínico: desafios do registro em uma pesquisa psicanalítica.

Silva, M. R.; Medeiros, C. B.; Arrosi, K. E.; Ferrari A. G. (2021). "Que bom que ele havia estranhado": considerações sobre a Metodologia IRDI. Psicologia Escolar e Educacional, v. 25. http://dx.doi.org/10.1590/2175-35392021226338 (no prelo)

Stern, D. S. (1997). A constelação da maternidade; o panorama da psicoterapia pais/bebês. Porto Alegre, RS: Artes Médicas.

Vygotsky, L. S. (1989). A formação social da mente. São Paulo: Martins Fontes.

Wanderley, D. B. (2013). Aventuras psicanalíticas com crianças autistas e seus pais. Salvador, BA: Ágalma.

Revisão gramatical: Davi Alexandre Tomm

E-mail: tomm.davi@gmail.com

Recebido em julho de 2020 - Aceito em outubro de 2021. 